\title{
The Influence of Household Procurement Strategies on Food Intake and Nutritional Status of Pre-school Children in Rural Western Kenya
}

\author{
Mary K. Walingo ${ }^{1} \&$ Francis M. Kidake ${ }^{1}$ \\ ${ }^{1}$ Maseno University, Maseno, Kenya \\ Correspondence: Mary K. Walingo, Maseno University, Maseno, Kenya. E-mail: marywalingo@gmail.com
}

Received: July 2, 2012 Accepted: December 22, 2012 Online Published: January 30, 2013

doi:10.5539/sar.v2n2p109 URL: http://dx.doi.org/10.5539/sar.v2n2p109

\begin{abstract}
A cross sectional survey design was set up to assess the influence of household procurement strategies on food intake and nutritional status of preschool children in from 196 households in Vihiga County, Kenya. Dietary diversity was positively correlated with food availability $(p<0.05)$. Increased consumption of bread and cereals, and, fruits and vegetables was influenced by food availability and food consumption (dietary diversity) $(<0.05)$. Roots and tubers, legumes and pulses, and carbonated drinks were the main contributors to food procurement strategies and availability $(\mathrm{F}=3.419, \mathrm{~F}$ sig $=0.02)$. Nutrition outcome was influenced by household socioeconomic status $(\mathrm{R}=0.189, \mathrm{p}$ value $=0.012)$ and income levels of households $(\mathrm{R}=0.246$, $\mathrm{p}$ value $=0.002)$, while procurement strategies had no effect on the nutritional status of the pre-school child. Household income levels determined food availability, diversity and intake.
\end{abstract}

Keywords: food procurement, dietary diversity, nutritional status, preschool children, Kenya

\section{Introduction}

High food prices have reduced food access for net buyers, with a greater impact of financial crisis emanating from the devaluation of the Kenyan shilling. This is expected to affect the income component of food access through high food prices in the market, job losses, a shrunk food basket which translates into reduced pay. Food intake and nutritional status of households is largely affected by poor access to food (WHO, 2008). The global food price increase coupled with the current financial crisis complicates the households' provisioning abilities and the general household food security situation. Most poor rural households depend on remittances from urban centres, and rely on foods purchased from the markets. Most of these families spend over $80 \%$ of their incomes on food (Beeriee \& Duflo, 2008). Food availability is changing across markets such that poor people who engage in markets face challenges accessing basic food that complicate food diversity and variety. Consumers of staple foods must now pay more for their food needs while sellers find the terms of trade working against them. Acreage under food crops in Vihiga County is very small and most of what is harvested is consumed within households and finished in a period of about a month on the average. Some farmers sell their harvest to meet other competing demands of the households' resources (Walingo, 2006).

Households' dietary diversity and intake of energy are reduce when food prices and increase and incomes decrease (Brinkman, de Pee, Sanogo, Subran, \& Bloem, 2010). Consumption of more expensive food items, portion sizes and the frequency of meals are all reduced. The reduction of food and nutrient consumption increases the severity of nutrient deficiencies and increases the prevalence of malnutrition (Bloem, de Pee, \& Darton-Hill, 2005; Gitau, Makasa, Kasonka, Sinkala, Chintu, Tomkins, \& Filteau, 2005; Sztam, Fawzi, \& Duggan, 2010; Sari, de Pee, Bloem, Sun, \& Thorne-Lyman, 2010; de Pee, Bloem, Sari, Sperkarin, Tiionn, Kosen, Muhilal, \& Satoto, 2010). Further, adults adopt smothering strategies where children's food consumption is highly prioritized over their own. (de Pee et al., 2000). Such households become vulnerable to malnutrition. Malnutrition accounts for an estimated 2.2 million under- five child deaths annually (Black, Allen, Bhutta, Caulfield, de Onis, Ezzati, Matthews, \& Rivera, 2008), and the situation is worsening with increasing food prices amidst collapsing economies. Families now buy small quantities of food, paying higher per-unit prices (Khor, 2008), amidst shrinking income streams. Foods purchased are monotonous and in small quantities that fail to meet the recommended dietary allowances for foods and nutrients. 
Households develop coping strategies ranging along a continuum of stages according to the severity of food insecurity that impact on their food consumption levels and nutritional status. Diversity of foods in the markets is mainly determined by price and the purchasing ability of the people. These factors interact to influence household food consumption and nutrition status of a household. This paper seeks to discuss the influence of food procurement strategies food intake and nutritional status of preschool children, and assess the level of food diversity in households in rural Kenya.

\section{Methods}

\subsection{Study Site}

Sabatia Division in Vihiga County, Kenya is located on the edge of Rift Valley, in the Lake Victoria basin, standing at an altitude of about 1,300 M to 1,500 M above sea level, and lies between latitude 00 and 0015 North. The Division has undulating hills and valleys. The Sabatia transversed by a number of streams and has an equatorial type of climate. The average annual precipitation is $1900 \mathrm{~mm}$ and rainfall is distributed throughout the year in seasons of long rain (April-August) and short rains (October-November). Temperature ranges between $14^{\circ} \mathrm{C}$ and $32^{\circ} \mathrm{C}$. These climatic conditions are ideal for the cultivation of a variety of crops, both subsistence and cash crops, and for dairy and livestock farming. Yet Sabatia is often referred to as 'a net importer of food' though there is room for improved productivity in crops and animals. The Sabatia has an average area of $110.4 \mathrm{~km}^{2}$, Sabatia Division is the most densely populated Division in the District. This Division has a low lying and agriculturally viable area. These favorable conditions have in part played a leading role in controlling rather contributing to increased settlement and overpopulation in the County. The importance accorded to ancestral land by the local community has also discouraged migration of this people in order to decongest the overstretched land resource. Sabatia has a high concentration of marginal and smallholder farmers

\subsection{Study Population}

Sabatia Division in Vihiga County has a total population of pre-school children of 19,672 accounting for $15.3 \%$ of the total population. The pre-school children were the major subjects of the study with their care-givers sampled as the respondents who provided information on the socio-economic and demographic status of their households and the food and nutrient intake of the pre-school children Small scale food vendors provided information on food imports and availability in the study area, and were the key informants about commercial activities involving food movement in the community.

\subsection{Study Design and Sample Selection}

A cross sectional survey design was set up to collect food procurement, procurement, consumption and nutrition status of preschool children in Vihiga county, western Province of Kenya. Quantitative approach was adopted for the collection of information on the selected variables using interview schedule, questionnaire, twenty-four hour dietary recall method, and food checklist. A household qualified to be included in the study if it had a pre-school child within the age range of 24 and 59 months. One pre-school child from each household was selected to be included in the study. About 196 pre-school children were randomly selected for the purpose of the study. Anthropometric and food and nutrient intake or the pre-school children were information measured. Markets in the county were visited on scheduled market days to assess the food availability in the County. Food vendors in markets accessible to households were randomly selected for the purpose of identification of the types of food available to households. Food vendors qualified for the study if they had been operating in the selected market for a period of over three years. Twenty small scale food vendors were randomly selected for the in-depth market study of food imports and availability.

\subsection{Measurement of Variables}

Food consumption was measured using a food consumption frequency index for eight food groups and dietary energy supply as methods to judge the child's dietary diversity, dietary composition, quantity (amount consumed) and dietary adequacy. A food checklist was used to collect information from food vendors on foods available in the market and food trade as a strategy of food procurement in households, and, also to collect information on food consumption in households. Food groups used in the food frequency questionnaire included; bread and cereals, legumes and pulses, roots and tubers, fruits and vegetables, meats and meat products, fats and oils and carbonated drinks. The food vendors provided information on food trade in the division. A food vendors questionnaire and observation checklist, were used to solicit information on demography, socio-economic status, food procurement strategies apart from trade and agricultural data. The food vendors provided information about the commercial activities involving food in the County. Food procurement was measured by a household food availability index for five major food groups. Food procurement strategies was measured using household food production estimates 
(proportion of household food stocks and animal holding), food trade i.e. changes in volumes of food trade of the business men questionnaire) and household food purchases, house hold food remittances among others. Coping strategies was measured using the common household coping mechanisms. Food trade was measured by a market survey of major food groups trade and demand for major staple foods from the local market while house hold food procurement was measured using the food budget. As an outcome of household food, nutritional status was measured using age, weight and height measures indicating changes in body proportion or consumption as a result of nutritional inadequacy.

\subsection{Data Analysis}

The chi-square test statistic was used to test the hypothetical association in both daily household expenditure on food as an outcome and their monthly income estimates. The linear correlation coefficient was used to decide on the statistical significance of the relationship between food procurement and food procurement and food consumption (independent variable) and nutrition status (dependent variable) respectively. However, since food consumption is dependent on food procurement, it was therefore partly treated as a dependant variable. Multiple regression analysis was then employed to try and identify the exact nature of their linear relationship.

\section{Results}

\subsection{General Socio-Demographic and Income Characteristics}

The mean age of caregivers was $32.71( \pm 9.99)$ years while that for the preschool children was $41.14( \pm 9.86)$ months. Families were relatively young with women bearing the burden of childcare. The average household size was 6.4, with about two children below five years of age. The average education level of caregivers was 8.55 $( \pm 2.79)$ years of primary education. As a whole, $97(55.1 \%)$ caregivers that had enrolled for primary education stayed in school for an average of about seven years. Only a total of 37 mothers $(19 \%)$ were either informally or formally employed while 151 (79\%) caregivers were unemployed. The mean number of household members who were reported as employed was $1.47( \pm 0.870)$ while a total of 22 mothers $(12.5 \%)$ doubled as caregivers and household heads (bread winners). At least 69 (39.3\%) caregivers were in male-headed households (the father as bread winner) while $80(45.4 \%)$ caregivers were in dual-headed households (bread winning as a collective responsibility for all in the household). Many households had male bread winners (fathers). The earner dependency ratio was $0.343( \pm 0.272)$. Household income streams was estimated from common rural income resources such as money remittances, proceeds from cash crops, livestock farming, small scale businesses, poultry keeping among others revealed that about two thirds of the households earned incomes below Kenya shillings (Ksh) 1,904 equivalent to 22.4 US dollars a month. Twenty nine (15\%) of the households did not qualify their incomes. If converted to monthly estimates, household daily expenditure on major food groups exceeded their regular incomes. About 96 (50\%) of the households had total monthly incomes below Ksh. 2500 (29.4 US Dollars) and about 171 (89\%) households spent less than Ksh. 200 (2 US dollars) food daily.

Table 1. Household food security classification according to the duration of harvested food stocks

\begin{tabular}{llll}
\hline Duration of Food Stocks & \multicolumn{2}{l}{ Farming Season (Percent) } & Food Security Classification \\
\hline \multirow{3}{*}{ From Season to Season } & Long Rains & Short Rains & \\
More than a month & 42.6 & 8.4 & Food Secure \\
About one month & 18.3 & 33.5 & Seasonally Food Secure \\
Less than a month & 10.5 & 26.2 & Seasonally Food Secure \\
Has no food harvest & 8.9 & 17.8 & Chronically Food Insecure \\
\hline
\end{tabular}

\subsection{Food Procurement Methods}

The overall food remitters to households were relatives (48\%) and family members (27\%). At least $47 \%$ of the households received food remittances every monthly from family members. Majority of relatives other than the immediate nuclear family provided food at least twice a year. Food remittances as a strategy played a pivotal role in household food procurement. The average household land size in the division was $1.12( \pm 1.127)$ acres with average animal holding capacity recorded as 6 poultry and 2 cattle per household. Households' yearly productivity of drought resistant crops such as sorghum and millet was below one bag ( $0.3 \mathrm{bags})$. Households' reported 
increased food scarcity in the period succeeding the short rains' harvest. Of households interviewed (Table 2), only $12.6 \%$ reported to have harvested enough food after the long rain season as compared to only $8.4 \%$ after the short rains season. Up to $8.9 \%$ of the households did not harvest food from the long rains seasons and $14.1 \%$ did not harvest after the short rains season. Most households could not depend on own production for staple food supply of their households, introducing food instability in the area. The chronically food insecure households were in the short rains season was $31.9 \%$ compared with only $19.4 \%$ in the long rains season.

About $89 \%$ of the households relied on food purchases daily, and spent up to 200 Kenya shillings (about two dollars) a day (Table 2). This expenditure exhausted all the household earnings for the day. Food purchases increased in the months of October-January and remained low in the month of May-June during the harvest period. About $48 \%$ of the households received remittances from relatives, with $47 \%$ of these households receiving remittances every month. Remittances played a pivotal role in household food procurement and stabilized household food reserves. The overall food procurement methods included food purchases $(35 \%)$, own food production (33\%), food remittances $(18 \%)$, payments in kind $(8 \%)$ and gifts $(6 \%)$.

Table 2. Monthly and daily income expenditure pattern on food purchases

\begin{tabular}{llllll}
\hline \multicolumn{6}{l}{ Daily Expenditure on Food in Kenya Shillings (Kshs) } \\
\hline Monthly income & $<100$ & $100-200$ & $201-300$ & $>300$ & Total Expenditure \\
$<2500$ & 2.6 & 22.4 & 1.6 & 0 & 50 \\
$2500-5000$ & 4.2 & 26.6 & 4.2 & 0 & 34.9 \\
$5001-7500$ & 1.6 & 3.1 & 2.1 & 0 & 6.8 \\
$7501-10000$ & 2.6 & 1.6 & 0.5 & 1 & 5.7 \\
$>10000$ & 0.5 & 0.5 & 0.5 & 1 & 1.6 \\
Total & 34.9 & 54.2 & 8.9 & 1.6 & 100 \\
\hline
\end{tabular}

$\chi=159.401, \mathrm{df}=20, \mathrm{p}=0.000$

\subsection{Market Survey of Food Stocks}

The mean lifespan of businesses at the time of the survey was 6.5 years. Nine retail shops and 8 food stalls, 2 groceries and 1 kiosk were surveyed. In the survey 11 food vendors mainly traded on bread and cereals, 4 traded on legumes and pulses. And 3 vendors traded on roots and tubers. The contribution of bread and cereals to local food trade in this area was significant. The contribution of food purchases, food production and food remittances to household food procurement was substantial, and households in the area could not entirely depend on own production for food supply due small land sizes. Only one food vendor had not stocked bread and cereals while 13 of them had not stocked both roots and tubers and, meat and meat products. Twelve food vendors of the bread and cereals group had reported high demand as compared to two vendors of legumes and pulses and 3 vendors of fruits and vegetables. The demand for meat and meat products among the food vendors sampled was the lowest. From analyzing recall data of monthly sales by the food vendors, it was noted that towards the end of every year, the total sales index score of food vendors increased gradually. However, a dramatic drop in sales was recorded in January just after the December period when there was a high demand for food due to the festive nature of the season. On average, many food vendors recorded low sales during the period between January and May. The steady rise in volume of sales was momentarily interrupted between June and July and between September and October. The volume and flow of foodstuff among food vendors could be attributed to increased household income other than on household food production. Transactions were extensively made during the final months of the year probably because of the festive season, reduced household expenditures on education and farming as well as increased remittances. The low food trade during the earlier months of the year could be attributed to low household disposal income for the food budget.

\subsection{Coping Strategies}

Five common coping strategies to food consumption were identified included periodic changes on the diet, a practice common in about $70 \%$ of the households and borrowing in $63 \%$ of the households. About $41 \%$ of the households reduced each household member's share of food while $38 \%$ of the households opted for maternal buffing. At least $28 \%$ of the households resigned to the fate of hunger. Households replaced superior foods with 
less superior foods for example common staples such as maize meal were replaced with roots and tuber or green bananas, red meat with dried small fish and tea without milk. Serving lighter food changed consistency of food eaten, like, serving of light porridge made from dry cereals in place of 'ugali', and diluted and sugarless milk or black tea in place of sweetened whole milk or tea with milk. By reducing the variety, and quantity of ingredients especially for composite meals, dietary quality of food served was eventually compromised. As incomes dwindled, households reduced the share of foods eaten by cutting down on the frequency of consumption of meals in a day, and on the amounts served. At times the amount of food available was not enough for all family members. This prompted older people in the family particularly mothers to surrender their share of food to their young ones. If nothing was available to be shared, then members retired to bed without having eaten anything. A look at these coping strategies reveals a pattern in severity of household experiences. The most popular strategies such as change of diet and borrowing were less severe as compared to the least popular strategies i.e. maternal buffering and staying hungry.

\subsection{Food Intake}

Milk and milk products had a mean frequency consumption index score of 7 , fruits and vegetables, breads/cereals, and fats/oils had a consumption index of six. Legumes/pulses, and roots/tubers had a score of four, while meat/meat products and carbonated drinks had the least mean scores of 3 and 2 respectively. The pattern of food consumption among preschool children reflected the food purchasing priorities in the household. Preschool children most frequently consumed cereals and milk, a common recipe for porridge, which is often used as a weaning diet among many rural folks. However, their diet comprised of plant protein than meat and meat products possibly due to price complications. Dietary diversity (or the frequency of consumption of the above seven food groups) was positively correlated with household food availability $(\mathrm{p}<0.05)$. Increased consumption of $\mathrm{bread} /$ cereals and fruits/vegetables resulted in a negative association between household food availability and food consumption (dietary diversity) $(<0.05)$. Roots/tubers, legumes/pulses, and carbonated drinks were the main contributors to household food procurement and availability $(\mathrm{F}=3.419, \mathrm{~F}$ sig. $=0.02$. These food groups are least consumed in households thus their procurement and consumption implied that households were able to access common staple foods that are basic and still remain with resources adequate for other food groups that are of higher economic value.

\subsection{Nutrition Status of Preschool Children}

The mean age of the preschool children was about 42 months, with a mean height of $93 \mathrm{~cm}$ and a mean weight of $13.8 \mathrm{kgs}$. About $23 \%$ of the preschool children were stunted both sexes combined. Stunting by sex revealed $22.2 \%$ girls and $23.7 \%$ stunted. The highest prevalence of malnutrition was stunting amongst the preschool children. Only $3.6 \%$ of the children were wasted. While no female was wasted, $5.9 \%$ of the male children were wasted. Prevalence of underweight was $14.3 \%$. About $29.6 \%$ of the males were underweight compared with only $7.4 \%$ of the females. Only $4.4 \%$ girls against only $1 \%$ boys were overweight. Generally more male children were malnourished compared to female children of the same age when malnutrition was measured by sex. The socioeconomic status $(R=0.189$, $p$-value $=0.012)$ and income levels in households $(R=0.246$, $p$-value $=0.002)$ predicted the nutrition outcome of preschool children. Addition of more independent variables (socio-economic status, yield of maize, household size, and age of caregivers) showed an appreciation in the value of multiple correlation coefficient (R) from 0.189 to $0.390(\mathrm{~F}=6.82, \mathrm{P}<0.05)$.

\section{Discussion}

Food procurement strategies, food intake, level of food diversity and nutritional status of preschool children are interconnected with household income levels and income streams forming the basic building blocks. Increased employment for caregivers assures households of continued income and food availability, and continued trade for the food vendors. Low income households are challenged to feed the large households of about six members with a high earner dependency ratio (0.343). Notably, the households' socioeconomic status and income levels are the major determinants of the nutrition outcome of preschool children in Vihiga. Households' socio-economic status, besides a complex interaction of a myriad of factors, play a great role in malnutrition outcomes through possible influence on the achievement of other determinants of nutritional status like better education for caregivers. Better education for caregivers increases the care giving quality, improves their chances of securing employment and thus increases household income required for increased food purchases and also increased diversification of income streams. Household decision-making involving food production, procurement and consumption are depended upon caretakers' knowledge of nutrition benefits of different foods and their ability to direct household resources towards food for home consumption.

High food prices have reduced food access for poor households who are net buyers and affected the income 
component of food. Food intake and nutritional status of households is largely affected by poor access to food (WHO, 2008) and intake. Low household incomes and increased food prices compromise food procurement and coping strategies. Most poor rural households depend on remittances from urban centres, and rely on foods purchased from the markets. Most of these families spend over $80 \%$ of their incomes on food (Beeriee \& Duflo, 2008). Households' daily expenditure on major food groups exceeded the regular incomes. Low incomes and expenditure on food have reduced food access for net buyers in Vihiga County, with high levels of chronic food insecurity (31.9\%). Poor access to food compromises the food intake and nutritional status of the pre-school children in households (WHO, 2008), and is further circumvented by the low income component of food access through high food prices in the market. Urban remittances are an important component of food procurement and coping strategies in households. The poor people who engage in markets are increasingly facing challenges accessing adequate basic food. Food intake is complicated by high food prices amidst low household incomes. Acreage under food crops continue to decrease with increased settlements and a further reduction in levels of food yields and harvests by households (Walingo, 2006; Brinkman, de Pee, Sanogo, Subran, \& Bloem, 2010). Low incomes influence the quantity and quality of food purchases and intake of pre-school children (Bloem, de Pee, \& Darton-Hill, 2005; Gitau, Makasa, Kasonka, Sinkala, Chintu, Tomkins, \& Filteau, 2005; Sztam, Fawzi, \& Duggan, 2010; Sari, de Pee, Bloem, Sun, \& Thorne-Lyman, 2010; de Pee, Bloem, Sari, Sperkarin, Tiionn, Kosen, Muhilal, \& Satoto, 2010), and a major contributor to poor nutritional status and low dietary diversity. Diversity of foods in the markets is mainly determined by price and the purchasing ability of the households.

Most poor rural households depend on remittances from urban centres, and rely on foods purchased from the markets. These households spend most of their incomes on food (Beeriee \& Duflo, 2008). In Vihiga adults adopt smothering strategies where children's food consumption is highly prioritized over their own (de Pee et al., 2000) and are vulnerable to malnutrition which accounts for increased child mortality rates (Black, Allen, Bhutta, Caulfield, de Onis, Ezzati, Matthews, \& Rivera, 2008). Poor households buy small quantities of food (Khor, 2008) that is not only monotonous but is low quality. Increasing opportunities for diversified income streams of households can increase food procurement, production and consumption through strengthened purchasing power of caregivers. Increased income streams interact to improve meaningful quality household food budgets, and better nutrition status of preschool children. Providing the basic staple, maize, significantly influence the nutrition status outcome for pre-school children, and forms a standard measure of food security in this area. Poor nutrition, especially stunting is a function of food availability for home consumption if other causes of wasting such as illness are held constant. Food security situation varies from season to season with more households suffering insecurity in the short rains season when harvests are low. Interventions in Vihiga County that include mechanisms to increase income and diversify household income streams can improve food security through increased adequacy and diversity of meals, and the nutritional status of pre-school children.

\section{Conclusion}

Poor nutrition status is a result of multiple factors interacting together and not necessarily food procurement strategies. Household coping strategies, food intake, and nutritional status of preschool children is a function of food availability, procurement and diversity. Although food procurement did not have a direct impact on nutrition status of preschool children, there is a complex interaction of multiple factors that include procurement that influence the nutritional status of pre-school children. Maize yield was significant in predicting the nutrition status outcome of preschool children in Vihiga County and its availability presents an index for and a measure of food security in the study area. Increasing availability and accessibility of maize in households may assure increased availability, procurement and intake in households. Generally rural households of Africa experience similar food procurement patterns especially with increasing settlements due to high population pressure that reduce available arable land.

\section{References}

Beneriee, C., \& Duflo, F. (2008). What is middle class about the middle classes around the world? J Econ. Perspet., 33, 299-317.

Black, R. F., Allen, I. H., Bhutta, Z. A., Caulfield, I. E., de Onis, M., Ezzati, M., ... Rivera, I. (2008). Maternal and child under nutrition: Global and regional exposures and health consequences. Lancet, 371, 243-260. http://dx.doi.org/10.1016/S0140-6736(07)61690-0

Bloem, M. W., de Pee, S., \& Darton-Hill, I. (2005). Micronutrient deficiencies and maternal thinness: first chain in the sequence of nutritional and health events in economic crises. In A. Bendich \& R. I. Deckelhaum (Eds.). Preventive nutrition: the comprehensive guide for health professionals. (3rd ed.). (pp. 689-709). Totowa (NJ): Humana Press. 
Brinkman, H. J., de Pee, S., Sanogo, I., Subran, L., \& Bloem, M. W. (2010). High food prices and global financial crisis have reduced access to nutritious food and worsened nutritional status and health. J. Nutr, 140(1), 153S161S. http://dx.doi.org/10.3945/jn.109.110767

De Pee, S., Bloem, M. W., Sari, M., Spekarin, D. D., Tiionn, R., Kosen, S., \& Muhilal, S. (2006). Indonesia’s crisis causes considerable weight loss among mothers and adolescents' malnutrition, 6, 2003-214.

Ekesa, B. N., Walingo, M. K., \& Mbagaya G. M. (2009). Dietary diversity, nutrition status and morbidity of pre-school children in Matungu division, Western Kenya. International Journal of Food Safety Nutrition and Public Health, 2(2), 131-141. http://dx.doi.org/10.1504/IJFSNPH.2009.029279

Ekesa, B. N., Blomme, G., \& Garming, H. (2011). Dietary diversity and nutritional status of pre-school children from musa-dependent households in gitega (burundi) and butembo (democratic republic of congo. African Journal of Food, Agriculture, 11(4), 4896-4911.

Gitau, R., Makasa, M., Kasonka, I., Sinkala, M., Chintu, C., Tomkins, A., \& Filteau S. (2001). Maternal micronutrient status and decreased growth of Zambian infants born during and after the maize price increases resulting from the southern African drought of 2001-2. Public Health Nutr., 140, 113-123. http://dx.doi.org/10.3945/jn.109.110569

Khor, G. L. (2008). Food-based approaches to combat the double burden among the poor: challenges in the Asian context. Asia Pac. J. Clin Nutr, 17(S1), 111-115.

Sari, M., de Pee, S., Bloem, M. W., Sun, K., Thorne-Lyman, A., Moench-Pfanner, B., ... Semba, R. D. (2010). Higher household expenditure on animal- source and nongrain foods lowers the risk of stunting among children 0-59 months old in Indonesia: Implications of rising food prices. $J$ Nutr., 140, 195-200. http://dx.doi.org/10.3945/jn.109.110858

Sztam, K. A., Fawzi, W. W., \& Duggan C. (2010). Micronutrient supplementation and food prices in HIV treatment. J Nutr, 140,113- 123.

Walingo, M. K. (2006). The Role of Education in Agricultural Projects for Food Security and Poverty Reduction in Kenya. International Review of Education, 52(3-4), 287-304. http://dx.doi.org/10.1007/s11159-006-0008-7

WHO. (2008). The global food crisis: implications for health of people in the African Region. An information note from the WHO Regional Office for Africa. 